\title{
The decision to opt for abortion
}

\section{Sam Rowlands}

\section{Introduction}

More than 200000 women have an abortion each year in Great Britain. 1,2 There is extensive experience of providing abortion care; with this are associated some widely held but inaccurate views on how to assist (or in some cases obstruct) women at the decision-making stage. The socalled 'post-abortion traumatic stress syndrome' is not recognised by national or international bodies of psychiatrists. $^{3}$

This review will demonstrate the wealth of evidence relating to abortion decision-making and will show how some common policies and service delivery practices are out of step with that evidence. The review starts by examining why women choose abortion and then looks at how this decision is reached. Finally, evidence is presented regarding the need for counselling.

This review does not cover peri-abortion contraceptive use or men's experiences of abortion. Nor does it consider research on the practicalities of the referral process, administrative reasons for delay, and attitudes of professionals consulted. Consideration of psychological consequences of abortion is limited to predictors of poor outcome. Finally abortion for fetal abnormality is not included. Reviews, guidance or recent studies covering all these topics are available. ${ }^{4-9}$

Only studies from developed countries are cited because of major differences in health systems. Only studies from settings with well-established legal abortion are cited because of the distorting impact on decisionmaking of restrictive legal systems, illegality or emphasis on psychiatric grounds. In this context, studies from the early years of legalised abortion are not given undue weight as professional opinion, not to mention societal values, changes and in time less emphasis is placed on psychiatric assessment.

Scientifically rigorous studies on the emotions, psychology and psychiatry are hard enough to perform, but in the field of abortion there are particular difficulties. Women who choose abortion cannot ethically be subjected to endless questions on how they feel; baseline assessments before pregnancy are impossible and these women tend to be resistant to follow-up. Nevertheless, attempts at such studies are present in the literature.

A literature search was conducted for the years 1967 (the year of the passage of the Abortion Act) to the present date using the terms 'pregnancy' or 'abortion' and 'decision' or 'counsel' as text words in MEDLINE, POPLINE, CINAHL and PsycINFO. Readers will see from the reference list that many studies identified are from the 1970 s and 1980s. In the author's opinion there are still applicable general principles in these studies even if methods of service delivery have moved on. If anything, the degree of psychological disturbance experienced by women nowadays is likely to be less as society has generally become more accepting of abortion.

J Fam Plann Reprod Health Care 2008; 34(3): 175-180

(Accepted 22 April 2008)

Warwick Medical School, University of Warwick, Coventry, UK Sam Rowlands, MD, FRCGP, Honorary Senior Lecturer

Correspondence to: Dr Sam Rowlands, Warwick Medical School, Gibbet Hill Campus, University of Warwick, Coventry CV4 7AL, UK. E-mail: sam.rowlands@warwick.ac.uk

\section{The decision-making process}

The decision-making process can be divided into five stages: 10

- Acknowledgement of the pregnancy

- Formulation of options: to continue the pregnancy and keep the baby, to continue the pregnancy and offer the baby for adoption or to undergo abortion

- Selection of continuation of the pregnancy or abortion by a balancing exercise

- Commitment to the chosen outcome

- Adherence to the decision.

The subject of adoption is beyond the scope of this review; readers are referred to the British Association for Adoption \& Fostering (www.baaf.org.uk).

A small study of Californian women having a pregnancy test showed that $78 \%$ had already decided on the outcome of a pregnancy, if this were to be confirmed; ${ }^{11}$ of those women who had decided in advance of receiving the test result, $88 \%$ were highly certain of their decision. The same phenomenon was seen in a small Swedish study. ${ }^{12}$ Deciding upon a course of action in principle before a pregnancy happens may facilitate adjustment because coping efforts are initiated upon learning of the pregnancy rather than after the period of time needed to reach a decision de novo.

More than $40 \%$ of women who eventually go through with an abortion experience a degree of shock when they learn they are pregnant. ${ }^{13}$ Other reactions are anger and disbelief, especially in those for whom it is a first pregnancy. ${ }^{14}$ Women describe feelings of suspension of normality, lack of control, isolation and disempowerment. Some women experience a sense of having been irresponsible, expressed as feelings of shame, stupidity and guilt. Correlates of high levels of distress before an abortion are fear of negative effects on the relationship, unsatisfactory relationship and not having had a child. 15

For some, the decision seems obvious and there is no internal struggle. However, for everyone making a decision around a major life event, it is a normal part of the decision-making process to experience ambivalence, the simultaneous existence of two opposed and conflicting attitudes or emotions. 16,17

The decision to opt for abortion is made rapidly on hearing that they are pregnant by more than half (56-72\%) of Scandinavian women who ultimately decide on abortion. ${ }^{18-20}$ Among 231 British women opting for abortion, $48 \%$ said they had never considered continuing the pregnancy and $58 \%$ said they had made up their minds before they first saw a doctor. ${ }^{13}$ Among women who had considered continuing, $19 \%$ of the total said they had only considered it at the very beginning and a further $13 \%$ of the total said they considered it from time to time. Three per cent of the total said they considered it right up to the night before the abortion. More than $85 \%$ of Norwegian women seeking abortion were sure about their decision before being seen at the hospital. ${ }^{21}$

\section{Reasons for opting for abortion}

In general, the reasons given by women for opting for abortion have outweighed any opposing reasons for continuation of the pregnancy. ${ }^{22}$ The options have been weighed in a 'balance sheet' approach. The more factors that are taken into account, the more likely the decision will be a satisfactory one. ${ }^{10}$ The more effort put into 
considering the various influential factors, the less likelihood there is of post-decisional regret.

The decision to opt for abortion by those faced with an unintended pregnancy is typically motivated by diverse and often interrelated reasons based on individual circumstances at that particular moment in time. ${ }^{23}$ Most women give concern for or responsibility to other individuals as a factor in their decision. It should be borne in mind that in England and Wales, $47 \%$ of women undergoing abortion have one or more children. ${ }^{1}$ Women feel responsible to children and other dependants, as well as considering children they may have in the future. ${ }^{24}$

The main groups of reasons given by those opting for abortion are: $13,23,25-28$

- Conflicts with job, education or existing children/dependants

- Financial and housing constraints

- Poor partner relationship, with the contemplation of single motherhood

- Family complete

- Not ready

- Lack of maturity.

In a study in the USA comparing women seeking abortion with those having antenatal care, whether the partner wanted a baby with them was a powerful influence on the likelihood of them seeking abortion. ${ }^{28}$ Reasons for having an abortion vary considerably by age. ${ }^{29}$ Younger women who have not begun their childbearing often report that they are unprepared for the transition to motherhood. ${ }^{23}$ Older women tend to express responsibilities toward existing children or other dependants as the key reason behind their decision to opt for abortion.

\section{Involvement of partner, significant others and professionals}

The first thing most women do when they suspect they are pregnant is to talk to somebody. ${ }^{13}$ These informal discussions are highly influential in the decision-making process. ${ }^{13,30}$ Those who speak to no-one apart from health professionals are more likely to be those who are separated, divorced or widowed. 13

In an interview survey of women in southern England who had already decided on abortion, their pregnancy had been discussed with an average of 5.6 others. ${ }^{30}$ In this study, the people most frequently involved in those discussions were gynaecologists, general practitioners, pregnancy counsellors, boyfriends, girlfriends, mothers and husbands. Of those people nominated by the women as their key discussants, pregnancy counsellors and girlfriends were most frequently reported to be able to ensure full discussion, followed by husbands, boyfriends and mothers. After 39\% of key discussions, the woman had a clearer idea of her course of action. A decision to opt for abortion was present in $72 \%$ of cases after the first discussion, rising to $86 \%$ and $89 \%$ after the second and third discussions, respectively. Fewer than $10 \%$ of women feel that they have been influenced by someone else in the decision to opt for abortion. ${ }^{20}$

\section{Ambivalence and fantasy}

Most studies are designed to record either/or thinking and linear logic which makes it impossible for respondents to express both positive and painful feelings. ${ }^{12}$ As has already been stated, ambivalence is defined as the presence of simultaneous conflicting emotions. Although ambivalence has been shown to be a predictor of poor outcome after abortion (see later), feelings of loss and guilt do not necessarily indicate that women later regret their decision or regard it as wrong. ${ }^{31}$ Abortion can be experienced as a relief and simultaneously as a loss coupled with feelings of grief. Feelings of ambivalence are an indication that abortion has a price, which implies that it is a more or less painful solution to an unwanted pregnancy. More than half of women experience conflicts of conscience in connection with the abortion. ${ }^{12}$ Sometimes ambivalence is florid enough to hamper the decision.

Other research has reinforced the importance of nonrational processes in the abortion decision. ${ }^{32}$ Women facing a pregnancy options decision have been shown to experience a wide range of fantasy processes. The majority of women entertained positive fantasies about ending the pregnancy, and fantasies of maternal detachment and pregnancy aversion. Despite the presence of a diverse range of fantasies, virtually all women endorsed the statement: "I think I should make my decision purely on the basis of practicalities".

About one-quarter of women who undergo abortion have experienced some degree of ambivalence during the decision-making process. ${ }^{19}$ By the time Scandinavian women are seen by specialist services, the extent of ambivalence has subsided to around $10 \% \cdot{ }^{17,18,20}$ In a British study from the early 1980s, $20 \%$ of women still showed significant ambivalence when seen at the hospital. ${ }^{33}$ Ambivalent women are at higher risk of poor psychological outcome than non-ambivalent women. ${ }^{34-36}$ Serious self-reproach following abortion is more frequent when women have been pressured in their decision by others. ${ }^{31}$

In a Danish survey of women carried out 2 days before their abortions, ambivalence was associated with opposition to abortion before becoming pregnant and with influence on the decision by financial/housing considerations. ${ }^{19}$ In this study, $16 \%$ of ambivalent women stated that their partner had made the decision to opt for abortion, whereas this figure was only $1 \%$ for nonambivalent women. Ambivalent women were also significantly more likely than non-ambivalent women to say their decision might have been different under other personal circumstances (mainly if their partner had wanted continuation of the pregnancy of if their financial situation had been better). ${ }^{19}$

\section{Change of mind}

It is well known that women requesting abortion do change their mind. Change of mind is correlated with the degree of ambivalence. All abortion providers see occasional cases of women backing out at the last moment, even in the anaesthetic room. In a Swedish study of 1419 women who requested abortion, 1285 (88\%) subsequently went through with an abortion. ${ }^{37}$ The remaining 134 chose to continue the pregnancy. Of those who had an abortion, $7 \%$ were in the second trimester whereas of those who continued the pregnancy $25 \%$ were in the second trimester. There were no striking socioeconomic differences between the groups.

\section{Delay and late presentation}

Delay can be attributed to blocks at one or more of the various stages of the decision-making process. ${ }^{10,38}$ What has been termed the 'recognition threshold' for a pregnancy varies from person to person; ${ }^{10}$ a high threshold may be associated with denial or other defence mechanisms. ${ }^{39}$ Second-trimester abortion is correlated with pre-existing social chaos, psychiatric illness, poverty, lack of access to medical information and care, extreme youth and other factors independently associated with psychosocial risk. ${ }^{40}$ Ambivalent women present later in pregnancy 41,42 and with more likelihood of psychological disturbance. ${ }^{42}$ Subtle and complex psychodynamic factors probably 
operate in some women presenting late for abortion. ${ }^{43}$ Very little is understood about denial of pregnancy 44 and whether or not this ultimate form of delay could be related to an extreme form of ambivalence. Emotional factors such as being in denial have been shown to be associated with a longer interval between a missed period and obtaining a pregnancy test. ${ }^{45}$

\section{Young people}

For some young women the decision to have an abortion is the first important decision of any type they have had to make. Young women make their decisions on abortion later than older women. ${ }^{18}$ This is reflected in the abortion statistics: $14 \%$ of under 20 -year-olds have second-trimester abortions, whereas the figure for those aged 20 years and over is $10 \% .^{1}$

Delays in pregnancy diagnosis often result in young women having to make their decision quickly. ${ }^{46}$ In the British survey of women who had decided on abortion, the vulnerable position of younger women stands out. 30 Younger women discussed their pregnancies with a larger number of people and were more likely to perceive key discussants as being opposed to abortion. These factors tend to militate against early and stable decisionmaking.

Young women have complex conflicts including denial, fantasies of the boyfriend marrying and rescuing them and fear of the boyfriend's and parents' response. ${ }^{47}$ Some young women conceal their pregnancy to avoid facing up to making a decision. 48,49

\section{Who needs pregnancy options and pre-abortion counselling?}

The term counselling is widely used in a loose sense to include provision of basic information. The techniques and materials used in such information provision are not examined here. It is best practice that all women receive objective, evidence-guided information to support them in making their choice around their unintended pregnancy, and that health professionals will check that this information has been received and understood. Such information is produced by the fpa (formerly the Family Planning Association) and the Royal College of Obstetricians and Gynaecologists (RCOG). $50-52$

Pregnancy options (decision) counselling provides women with time to look at their pregnancy and situation, explore all possible options and to make an informed choice when they feel ready to do so in as non-threatening an environment as possible. 16,53-55 Pre-abortion counselling should make women feel supported and confident in the choice they have made. The literature focuses on the former.

In this review the term counselling is used in its purer sense. Despite the fact that hard evidence of the benefits of abortion counselling is rare, 16 most would agree that such counselling should be available. ${ }^{56}$ The emphasis should be on what meaning in psychodynamic terms the pregnancy and abortion has for a particular woman at this time in her life. ${ }^{57}$ The abortion and its antecedents can be viewed as a crisis in her life and the opportunity seized to take stock of her life. Women may be more accessible to help than at a later stage when they have consolidated their defence mechanisms. ${ }^{39}$

A definite answer may not be immediately forthcoming following pregnancy options counselling. Nevertheless, time is of the essence in relation to abortion, so those doing the counselling may need to be more focused and direct than in other types of counselling work. Counselling should be confidential, non-directive, non-judgemental, supportive and understood by the woman to be independent of any assessment for legal approval for abortion. 50,51 Women sometimes feel they have to 'make a case' for their abortion as they feel judged and stigmatised by the health professionals they are seeing. Women 'making a case' in this way tend to suppress their doubts and anxieties. An integrated care pathway for discussing pregnancy options has been developed. ${ }^{58}$ Greater use of such integrated care pathways would improve both the co-ordination and the consistency of abortion care.

In a New Zealand study of 287 consecutive women undergoing abortion, $94 \%$ said that they had already made their decision prior to counselling and $4 \%$ reached their decision during the counselling session. ${ }^{59}$ In a study conducted in 1979, 162 English women requesting abortion were interviewed by a medical social worker; after counselling, 15 women $(9 \%)$ had decided to continue with their pregnancies. ${ }^{33}$

The following factors have been identified by experienced counsellors as predictors of poor psychological outcome following abortion. ${ }^{60}$ The first two of these factors are supported by hard evidence:

- A history of mental health problems ${ }^{34-36,61-65}$

- Poor practical or emotional support from family and friends $26,66,67$

- Possibility of being coerced by parents, family members, partners or others ${ }^{34}$

- Emotionally, physically or sexually abused or subjected to neglect

- Adopted

- Children of teenage and/or single mothers

- A history of previous abortion, stillbirth, miscarriage or other gynaecological problems

- Adolescents, particularly under-16s

- Experience of other losses in life

- Pregnancy initially wanted but circumstances changed

- Emotional responses seem extreme (e.g. very upset, calm, distant or jovial)

- A religious, cultural or societal background with antiabortion or strongly held moral views 62

- Late gestation.

In Sweden, counselling has been shown to be used more often for women who have not already made a decision in principle before becoming pregnant. ${ }^{18}$ Women who should be targeted as potentially in need of counselling are the minority who have been identified as overtly ambivalent or who belong to one of the above groups. Of these factors the most important are probably a history of mental health problems, lack of support and suspected coercion. ${ }^{68}$ However, it must always be borne in mind that counselling is, by definition, something that is freely entered into and that it should not be imposed. 69 Even when counselling is taken up and carried out by professionals, satisfactory outcomes are only possible when the woman expresses her feelings openly. There are occasional cases of subsequent regret in which pertinent feelings and facts have been deliberately or unintentionally concealed by the woman during counselling.

As to who should do the counselling, counsellors themselves would recommend only those who are trained to diploma level on a course recognised by the British Association for Counselling and Psychotherapy (www.bacp.co.uk). ${ }^{60}$ Primary care professionals found in an audit that only two of about 300 consecutive women requesting abortion needed referral; the others were counselled by general practitioners or practice nurses. ${ }^{70}$ Most community-based National Health Service (NHS) abortion assessment services are now nurse-led; nurses are well able to provide counselling. 55,71 
When the women themselves were asked whether they thought they needed to talk to a doctor about the decision to have an abortion or not, two-thirds thought it unnecessary. ${ }^{13}$ A qualitative study in London showed that most women do not expect health professionals to get involved in the decision-making process. ${ }^{72}$ Health professionals are often not responsive to women's needs. Requiring women to discuss the decision on more than one occasion with different health professionals is particularly inept on the part of service providers. However, women who do not discuss their decision with friends or family may welcome the opportunity to do so with professionals Those who are targeted for counselling should be given a clear explanation that the purpose is not to change their mind or to question their decisions.

\section{Discussion}

The fact that a majority of women have already made up their mind about an unintended pregnancy before it is confirmed is something that is not widely recognised. What is perhaps more widely established is that many women make their decision rapidly and that they are sure about their decision. Any lingering doubts tend to be dispelled by discussions with family, friends or primary care professionals; these discussions largely occur before contact with secondary health services. Therefore, for a large majority of women requesting abortion, the concept of providing an optimal environment for them in which to reach their decision is redundant and options counselling is superfluous.

Nevertheless, for the significant minority who, by contrast are undecided, suitable services need to be available. Women themselves are clear that they do not want mandatory options counselling and the evidence cited in this review supports this position. Nevertheless, all women should be asked if they are sure about their decision and if they have been subjected to pressure or coercion from any quarter in making that decision. Anyone identified as unsure or under pressure should be offered options counselling. The concept of mandatory counselling, as in 32 of the 50 states in the USA, is unscientific. In this context counselling is more information provision than true counselling, but the content of the mandatory information to be provided is inaccurate in many cases (e.g. a purported association between abortion and breast cancer). ${ }^{73}$

Women requesting abortion should be screened for indecision, coercion and for predicting factors for poor outcome. Making women who have reached their decision wait for their procedure creates further unwarranted anxiety for the woman and increases the risk of morbidity 74 and mortality 75 from abortion. Same-day ('lunchtime') abortions, where women have their treatment initiated or completed on the day they are assessed by the abortion provider, have been in existence for some years. Such services have not been formally evaluated and studies on their benefits would be useful. Nevertheless, there is no suggestion that same-day abortions are unsafe from a psychological perspective. A compulsory waiting or 'cooling off' period is enshrined in abortion law in countries such as Belgium, France, Germany, Italy and The Netherlands and in 24 of the USA states; this is nonsensical for women who have made their decisions by the time they present to health professionals. Cooling off periods start from the time the woman is seen by a professional and vary from 24 hours to 7 days. There is no evidence that such a cooling off period protects women's mental health. In addition, such laws have been shown to lead to a shift towards the performance of abortions at later gestations. ${ }^{76}$
Attempts in this country through Ten Minute Rule Bills in October $2006^{77}$ and June $2007^{78}$ to introduce cooling off periods together with mandatory counselling were rejected by Parliament on both occasions.

In the UK, the Department of Health requires that providers outside the NHS who may refer women directly to clinics and hospitals are registered as Pregnancy Advisory Bureaux by the Secretary of State. ${ }^{79}$ The House of Commons Committee on Science and Technology recommended that, to ensure that no patients are misled, the Government should consider ways of ensuring that all those claiming to offer pregnancy counselling services make the information recommended in the $\mathrm{RCOG}$ guideline ${ }^{74}$ available, or indicate clearly in their advertising if they do not support referral for abortion. ${ }^{80}$ The Government has undertaken to work with the Committee of Advertising Practice to consider whether an advertising code applicable to pregnancy counselling would be appropriate. ${ }^{81}$ The need for the recent tightening of General Medical Council guidance on conscientious objection ${ }^{82}$ indicates that all is not well with the way that pregnancy counselling is being conducted in the NHS either.

For women who display a pathological degree of ambivalence or who have predicting factors for poor outcome, individualised care should be offered. Professional counselling should be on hand for those who request it. Women may need more than one counselling session. In very rare cases a psychiatric opinion may be indicated. Inevitably there will be tensions between time needed for the decision-making process and advancing gestation, but it can never be right for a woman who is clearly undecided to be forced into an abortion. That is not to say that it is in any way wrong to reserve appointments for individuals that can be cancelled if they are not needed. 79

\section{Conclusions}

It appears that many women make decisions about pregnancy in principle as an abstract concept before they find themselves in that position. This may explain why most women make rapid decisions when they face an unintended pregnancy. A majority of women have had full discussions with those they trust before reaching abortion providers.

All women need evidence-guided information in order to make a fully informed decision. All women need a sympathetic and supportive milieu but few need formal counselling. Pregnancy options counselling should not be made mandatory as government policy or national law.

It would appear that bringing all women requesting abortion back for further discussions after they have made initial contact with primary care services is both unnecessary and harmful. Similarly, building time into abortion services for all women to reflect on their options is also unnecessary and harmful. Attempts to introduce mandatory counselling into the law should be resisted on scientific grounds.

\section{Acknowledgements}

The author is grateful to the two peer reviewers and Journal Associate Editor for their helpful comments, which significantly improved this review.

\section{Statements on funding and competing interests} Funding None identified.

Competing interests None identified.

\section{References}

1 Department of Health. Abortion Statistics, England and Wales: 2006. London, UK: Department of Health, 2007

2 Information Services Division (ISD) Scotland. Abortions. 
Scottish Health Statistics 2006. Edinburgh, UK: NHS National Services Scotland. http://www.isdscotland.org/isd/1918.html [Accessed 9 February 2008].

3 Stotland NL. The myth of the abortion trauma syndrome. JAMA 1992; 268: 2078-2079.

4 Bajos N, Lamarche-Vadel A, Gilbert F, Ferrand M Contraception at the time of abortion: high-risk time or high-risk women? Hum Reprod 2006; 21: 2862-2867.

5 Kero A, Lalos A. Reactions and reflections in men, 4 and 12 months post-abortion. J Psychosom Obstet Gynaecol 2004; 25: 135-143.

6 Medical Foundation for AIDS \& Sexual Health (MedFASH). Recommended Standards for Sexual Health Services. London, UK: MedFASH, 2005

7 Zolese G. Blacker CVR. The psychological complications of therapeutic abortion. Br J Psychiatry 1992; 160: 742-749.

8 Royal College of Obstetricians and Gynaecologists (RCOG), Royal College of Midwives, British Association of Perinatal Medicine, Department of Health. Further Issues Relating to Late Abortion, Fetal Viability and Registration of Births and Deaths. London, UK: RCOG Press, 2001.

9 House of Commons Science and Technology Committee. Scientific Developments Relating to the Abortion Act 1967 (Volume II HC 1045-II). London, UK: The Stationery Office, 2007.

10 Bracken MB, Kasl SV. Delay in seeking induced abortion: a review and theoretical analysis. Am J Obstet Gynecol 1975 121: 1008-1019.

11 Cohan CL, Dunkel-Schetter C, Lydon J. Pregnancy decision making: predictors of early stress and adjustment. Psychol Women Q 1993; 17: 223-239.

12 Kero A, Lalos A. Ambivalence - a logical response to lega abortion: a prospective study among women and men. $J$ Psychosom Obstet Gynaecol 2000; 21: 81-91.

13 Allen I. Counselling Services for Sterilisation, Vasectomy and Termination of Pregnancy. London, UK: Policy Studies Institute, 1985.

14 Harden A, Ogden J. Young women's experiences of arranging and having abortions. Sociol Health IIIn 1999; 21: 426-444.

15 Lauzon P, Roger-Achim D, Achim A, Boyer R. Emotional distress among couples involved in first-trimester induced abortions. Can Fam Physician 2000; 46: 2033-2040.

16 Rutledge M. Does counselling really help abortion patients? In Sachdev $\mathrm{P}$ (ed.), Perspectives on Abortion. Metuchen, NJ: Scarecrow Press, 1985; 223-235.

17 Hamark B, Uddenberg N, Forssman L. The influence of socia class on parity and psychological reactions in women coming for induced abortion. Acta Obstet Gynecol Scand 1995; 74: 302-306.

18 Holmgren K. Time of decision to undergo an abortion. Gynecol Obstet Invest 1988; 26: 289-295.

19 Husfeldt C, Hansen SK, Lyngberg A, Nøddebo M, Petersson B. Ambivalence among women applying for abortion. Acta Obstet Gynecol Scand 1995; 74: 813-817.

20 Törnbom M, Ingelhammar E, Lilja H, Svanberg B, Möller A Decision-making about unwanted pregnancy. Acta Obstet Gynecol Scand 1999; 78: 636-641.

21 Skjeldestad FE. The decision-making process and information needs among women seeking abortion. Results from 2 studies conducted with a 10-year interval, 1983-93 [in Norwegian] Tidsskr Nor Laegeforen 1994; 114: 2276-2279.

22 Allanson S. Abortion decision and ambivalence: insights via an abortion decision balance sheet. Clin Psychol 2007; 11: 50-60.

23 Finer LB, Frohwirth LF, Dauphinee LA, Singh S, Moore AM Reasons US women have abortions: quantitative and qualitative perspectives. Perspect Sex Reprod Health 2005; 37: $110-118$.

24 Jones RK, Frohwirth LF, Moore AM. "I would want to give my child, like, everything in the world." J Fam Issues 2008; 29: 79-99.

25 Smith RG, Steinhoff PG, Diamond M, Brown N. Abortion in Hawaii: the first 124 days. Am J Public Health 1971; 61: 530-542.

26 Shusterman LR. Predicting the psychological consequences of abortion. Soc Sci Med 1979; 13A: 683-689.

27 Bankole A, Singh S, Haas T. Reasons why women have induced abortions: evidence from 27 countries. Int Fam Plann Perspect 1998; 24: 117-127.

28 Santelli JS, Speizer IS, Avery A, Kendall K. An exploration of the dimensions of pregnancy intentions among women choosing to terminate pregnancy or to initiate prenatal care in New Orleans, Louisiana. Am J Public Health 2006; 96 2009-2015.

29 Sihvo S, Bajos N, Ducot B, Kaminski M. Women's life cycle and abortion decision in unintended pregnancies. J Epidemiol
Community Health 2003; 57: 601-605.

30 Ashton J. Patterns of discussion and decision-making amongst abortion patients. J Biosoc Sci 1980; 12: 247-259.

31 Lemkau JP. Emotional sequelae of abortion. Psychol Women Q 1988; 12: 461-472.

32 Allanson S, Astbury J. The abortion decision: fantasy processes. J Psychosom Obstet Gynaecol 1996; 17: 158-167.

33 Hare MJ, Heywood J. Counselling needs of women seeking abortion. J Biosoc Sci 1981; 13: 269-273.

34 Friedman CM, Greenspan R, Mittleman F. The decision-making process and the outcome of therapeutic abortion. $A m$ J Psychiatry 1974; 131: 1332-1337.

35 Lask B. Short-term psychiatric sequelae to therapeutic termination of pregnancy. Br J Psychiatry 1975; 126: 173-177.

36 Ashton JR. The psychological outcome of induced abortion. $\mathrm{Br}$ J Obstet Gynaecol 1980; 87: 1115-1122.

37 Söderberg H, Andersson C, Janzon L, Sjöberg N-O. Continued pregnancy among abortion applicants. Acta Obstet Gynecol Scand 1997; 76: 942-947.

38 Ingham R, Lee E, Clements S, Stone N. Second Trimester Abortions in England and Wales. Southampton, UK: Centre for Sexual Health Research, School of Psychology, 2007.

39 Gelder M, Harrison P, Cowen P. Reactions to stressful experiences. Shorter Oxford Textbook of Psychiatry. Oxford, UK: Oxford University Press, 2006; 151-173.

40 Stotland NL. Psychosocial aspects of induced abortion. Clin Obstet Gynecol 1997; 40: 673-686.

41 Kerenyi TD, Glascock EL, Horowitz ML. Reasons for delayed abortion: results of four hundred interviews. Am J Obstet Gynecol 1973; 117: 299-311.

42 Osofsky JD, Osofsky HJ, Rajan R, Spitz D. Psychosocial aspects of abortion in the United States. Mt Sinai J Med 1975; 42: 456-467.

43 Cancelmo JA, Hart B, Herman JL, Rashbaum WK, Stein JL. Psychodynamic aspects of delayed abortion decisions. $\mathrm{Br} \mathrm{J}$ Med Psychol 1992; 65: 333-345.

44 Wessel J, Gauruder-Burmester A, Gerlinger C. Denial of pregnancy - characteristics of women at risk. Acta Obste Gynecol Scand 2007; 86: 542-546.

45 Foster DG, Jackson RA, Cosby K, Weitz T, Darney PD, Drey EA. Predictors of delay in each step leading to an abortion. Contraception 2008; 77: 289-293.

46 Tabberer S, Hall C, Prendergast S, Webster A. Teenage Pregnancy and Choice. York, UK: Joseph Rowntree Foundation, 2000

47 Osofsky JD, Osofsky HJ. Teenage pregnancy: psychosocial considerations. Clin Obstet Gynaecol 1978; 21: 1161-1173.

48 Schreiber H. Adolescents from different socioeconomic backgrounds had different attitudes about teen pregnancy. Evid Based Nurs 2001; 4: 125

49 Seamark C. Design or accident? The natural history of teenage pregnancy. J Roy Soc Med 2001; 94: 282-285.

50 fpa. Pregnant and Don't Know What to Do? A Guide to Your Options. 2007. http://www.fpa.org.uk/attachments/published/ 683/PDF\%20Pregnant $\% 20$ and $\% 20$ don't\%20know\%20know\% 20what\%20to\%20do\%20April\%202007\%20.pdf [Accessed 9 February 2008]

51 fpa. Abortion: Your Questions Answered. 2007. http://www. fpa.org.uk/attachments/published/123/PDF\%20Abortion\%20Y our $\% 20$ questions $\% 20$ answered $\% 20$ July $\% 202007$.pdf [Accessed 9 February 2008].

52 Royal College of Obstetricians and Gynaecologists. About Abortion Care: What You Need to Know. 2004. http://www.rcog.org.uk/resources/public/pdf/aboutabortioncare. pdf [Accessed 9 February 2008].

53 Cheetham J. Alternatives to termination - 1 Making the decision. Br J Fam Plann 1982; 8: 101-104.

54 Christopher E. Sexuality and Birth Control in Community Work (2nd edn). London, UK: Tavistock, 1987.

55 Simmonds KE, Likis FE. Providing options counseling for women with unintended pregnancies. J Obstet Gynecol Neonatal Nurs 2005; 34: 373-379.

56 Handy JA. Psychological and social aspects of abortion. $\mathrm{Br} \mathrm{J}$ Clin Psychol 1982; 21: 29-41.

57 Schmidt R, Priest RG. The effects of termination of pregnancy: a follow-up study of psychiatric referrals. $\mathrm{Br} \mathrm{J}$ Med Psychol 1981; 54: 267-276.

58 Mcllveen H. Pregnancy options. The Manual for Sexual Health Advisers. London, UK: Society for Sexual Health Advisers, 2004: 163-175.

59 Hunton RB, Spicer J. An evaluation of the counselling given to patients having a therapeutic abortion. Aust $N Z J$ Obste Gynaecol 1979; 19: 169-173.

60 Brien J, Fairbairn I. Pregnancy and Abortion Counselling. London, UK: Routledge, 1996 
61 Ford CV, Castelnuovo-Tedesco P, Long KD. Abortion: is it a therapeutic procedure in psychiatry? JAMA 1971; 218: 1173-1178.

62 Payne EC, Kravitz AR, Notman MT, Anderson JV. Outcome following therapeutic abortion. Arch Gen Psychiatry 1976; 33: 725-733.

63 Gilchrist AC, Hannaford PC, Frank P, Kay CR. Termination of pregnancy and psychiatric morbidity. $\mathrm{Br} J$ Psychiatry 1995; 167: 243-248.

64 Major B, Cozzarelli C, Cooper L, Zubek J, Richards C, Wilhite $\mathrm{M}$, et al. Psychological responses of women after first-trimester abortion. Arch Gen Psychiatry 2000; 57: 777-784.

65 Broen AN, Moum T, Bödtker AS, Ekeberg Ö. Predictors of anxiety and depression following pregnancy termination: a longitudinal five-year follow-up study. Acta Obstet Gynecol Scand 2006; 85: 317-323.

66 Belsey EM, Greer HS, Lal S, Lewis SC, Beard RW. Predictive factors in emotional response to abortion: King's termination study IV. Soc Sci Med 1977; 11: 71-82.

67 Moseley DT, Follingstad DR, Harley H, Heckel RV. Psychological factors that predict reaction to abortion. J Clin Psychol 1981; 37: 276-279.

68 Broome A. Termination of pregnancy. In: Broome A, Wallace L (eds), Psychology and Gynaecological Problems. London, UK: Tavistock, 1984; 60-76.

69 Landy U. Abortion counselling - a new component of medical care. Clin Obstet Gynaecol 1986; 13: 33-41.

70 Matthews P, Ball S. Counselling, psychological morbidity and termination of pregnancy [Letter]. J Fam Plann Reprod Health Care 2003; 29: 39.

71 Newton JR, Iddenden DA, Newton P. Abortion counselling by nurse specialists. Contraception 1979; 20: 429-439.

72 Kumar U, Baraitser P, Morton S, Massil H. Decision-making and referral prior to abortion: a qualitative study of women's experiences. J Fam Plann Reprod Health Care 2004; 30: 51-54.

73 Richardson CT, Nash E. Misinformed consent: the medical accuracy of state-developed abortion counselling materials. Guttmacher Policy Review 2006; 9: 6-11.

74 Royal College of Obstetricians and Gynaecologists (RCOG) The Care of Women Requesting Induced Abortion. (Evidencebased Guideline No. 7). London, UK: RCOG Press, 2004.

75 Bartlett LA, Berg CJ, Shulman HB, Zane SB, Green CA Whitehead S, et al. Risk factors for legal induced abortionrelated mortality in the United States. Obstet Gynecol 2004; 103: 729-737.

76 Joyce T, Henshaw SK, Skatrud JD. The impact of Mississippi's mandatory delay law on abortions and births. JAMA 1997; 278: 653-658.

77 Termination of Pregnancy Bill. Bill 41, 54/2. 2006. http://www.publications.parliament.uk/pa/cm200607/cmbills/04 1/07041.i-i.html [Accessed 9 February 2008].

78 Termination of Pregnancy (Counselling and Miscellaneous Provisions) Bill. Hansard HC Column 138, 5 June 2007. http://www.publications.parliament.uk/pa/cm200607/cmhansrd/ cm070605/debtext/70605-0004.htm [Accessed 9 February 2008].

79 Department of Health. Procedures for the Registration of Pregnancy Advice Bureaux. London, UK: Department of Health, 1999.

80 House of Commons Science and Technology Committee. Scientific Developments Relating to the Abortion Act 1967 (Volume I HC 1045-1). London, UK: The Stationery Office, 2007.

81 Primarolo D. Government Response to the Report from the House of Commons Science and Technology Committee on the Scientific Developments Relating to the Abortion Act. London, UK: Department of Health, 2007.

82 General Medical Council (GMC). Personal Beliefs and Medical Practice. London, UK: GMC, 2008.

\section{ERRATUM}

Society of Medical Writers, Fam Plann Reprod Health Care 2008; 34(2): 92

The Journal wishes to apologise for any inconvenience that may have resulted from the April 2008 issue listing the incorrect name and e-mail address for Professor Brian McGuinness, Chairman of the Society of Medical Writers. Further information on the Society is available by e-mailing Professor McGuinness at bwmcguinness1@hotmail.com.

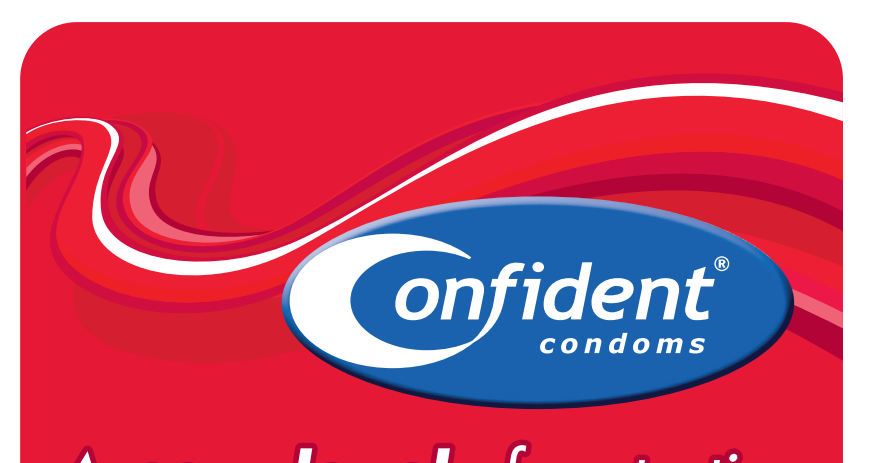

A new level of protection The only condom with vitamin $\mathrm{E}$
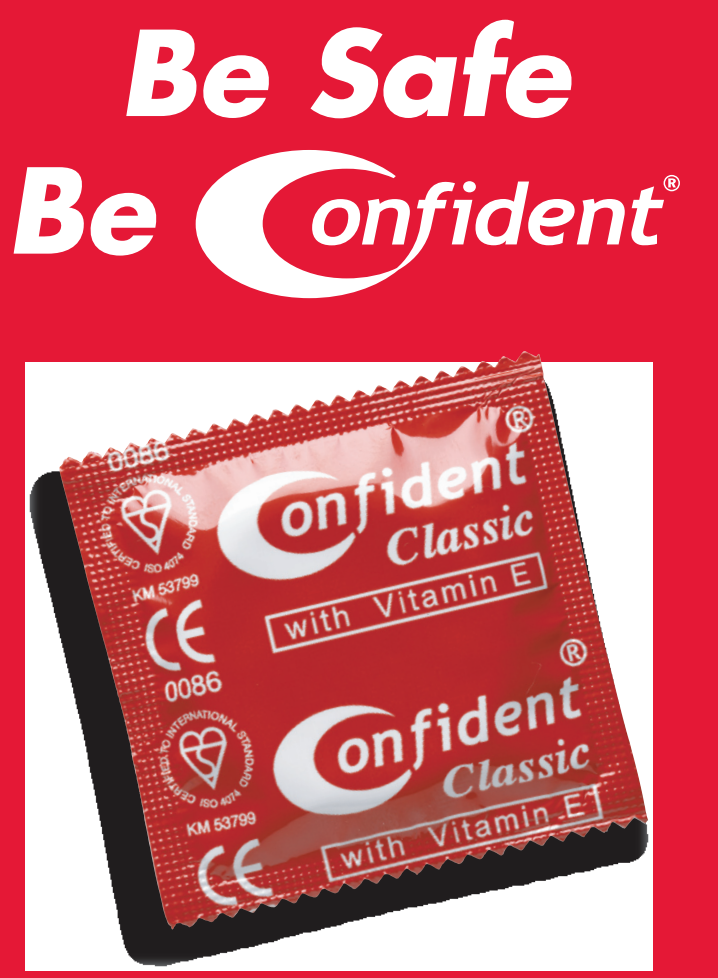

- Condoms odour masked and lubricated with Vitamin $E$

- Competitively priced packs in presentation boxes

- Customer support, advice, presentations and samples

- Anatomically shaped for greater comfort and sensitivity

Britannia Medicare Ltd, Innova Science Park, Electric Avenue, Enfield, Middlesex, EN3 7XU, United Kingdom

$\mathbf{T}+44(0) 2083504093 \mathbf{F}+44(0) 2083720112$ E info@britanniamedicare.com

www.britenniamedicare.com 